\title{
The High Cost of Taxi Regulation, with Special Reference to Sydney
}

\author{
PETER ABELSON ${ }^{1}$
}

\section{Abstract}

Numerous regulations govern entry, industry structure, service quality and prices for the Sydney taxi industry. The paper finds few efficiency or social reasons for these regulations and taxi performance is poor. On plausible assumptions, the net benefits from unrestricted entry into the Sydney taxi industry are in the order of $\$ 265$ million per annum. The productivity and service benefits of reforming entry would be greater if accompanied by reform of the anti-competitive control of the taxi radio networks over all taxi operators.

\section{Introduction ${ }^{2}$}

The taxi industry is heavily regulated in most Australian cities, with regulations covering the number of taxis, industry structure, service quality and prices. These regulations have been retained despite numerous Australian and international reviews finding that the taxi industry is over-regulated in Australia and other countries respectively (see Productivity Commission 1999; National Competition Council 2000; UK Office of Fair Trading 2003; OECD 2007). Moreover, in cities in New Zealand, Ireland, the Netherlands, Sweden and the United Kingdom where supply restrictions have been removed or loosened,

\footnotetext{
1 Visiting Scholar in the Faculty of Economics and Business, University of Sydney, and a part-time economic advisor to the NSW Treasury. Peter.Abelson@sydney.edu.au

2 I thank the two referees and the Editor for comments on the draft paper. All information in this paper is drawn from public sources or based on data that the author has collected from industry participants or observers. This paper is the academic research of the author, and the full responsibility of the author. It does not necessarily reflect the views of the NSW Treasury.
} 
'the results of these reforms have been highly positive, with reduced waiting times, increased consumer satisfaction and, in many cases, falling prices being observed' (OECD 2007: 8).

In this paper I describe the regulations on the taxi industry in Sydney and discuss the consequences, discuss public policy objectives and estimate the benefits of deregulation, discuss why the government is so reluctant to deregulate the industry and conclude with policy suggestions. While the focus is on Sydney, similar issues exist in most other Australian cities.

\section{The Taxi Industry in Sydney}

Figure 1 provides a sketch of the taxi industry in Sydney. There are four main participants: owners of taxi 'plates', operators of taxis, taxi radio networks and taxi drivers. ${ }^{3}$ A plate is essentially a piece of paper conferring on the owner the right to operate a taxi. Operators of taxis must acquire a plate (as well as an operator's licence by undertaking a training course) in order to operate a taxi but they often lease the plate from a plate owner.

About 3600 entities own 5174 taxi plates in Sydney (IPART 2009). Some 75 per cent of the plates are perpetual taxi licences mostly issued free before 1990 . The other 25 percent of plates issued or sold by the Government since 1990 include: 'ordinary licences' (10-50 years), 'short-term licences' (1-6 years), 479 wheelchair-accessible taxi (WAT) licences and 269 time-restricted taxis.

About 4000 operators manage the 5174 taxis. Eighty per cent of the operators lease a taxi plate; 20 per cent own a plate. Taxi operators manage, maintain and insure the taxis. They may drive the taxi or bail (lease) it to a driver. Critically, government regulation requires all operators to be affiliated to an authorised taxi radio network. These networks provide various services including a radio booking system, a GPS tracking system and alarm monitoring service.

The NSW Independent Pricing and Regulatory Tribunal (IPART 2009) lists 11 radio networks in Sydney. However, the Combined Communications Network (CCN), which is wholly owned by the publicly listed company Cabcharge, owns six of these radio networks and hosts another (St. George), so there are in effect six 'independent' networks. These are CCN (3341 taxis including St George): Premier (947 taxis), Legion (525 taxis), Manly and RSL which share a radio office (322 taxis combined) and Lime (67 taxis) - see IPART (2009) and Abelson (2010).

3 More detail on the taxi industry in Sydney can be found in IPART (2009) and Abelson (2010). 
Figure 1: Structure of taxi industry in Sydney

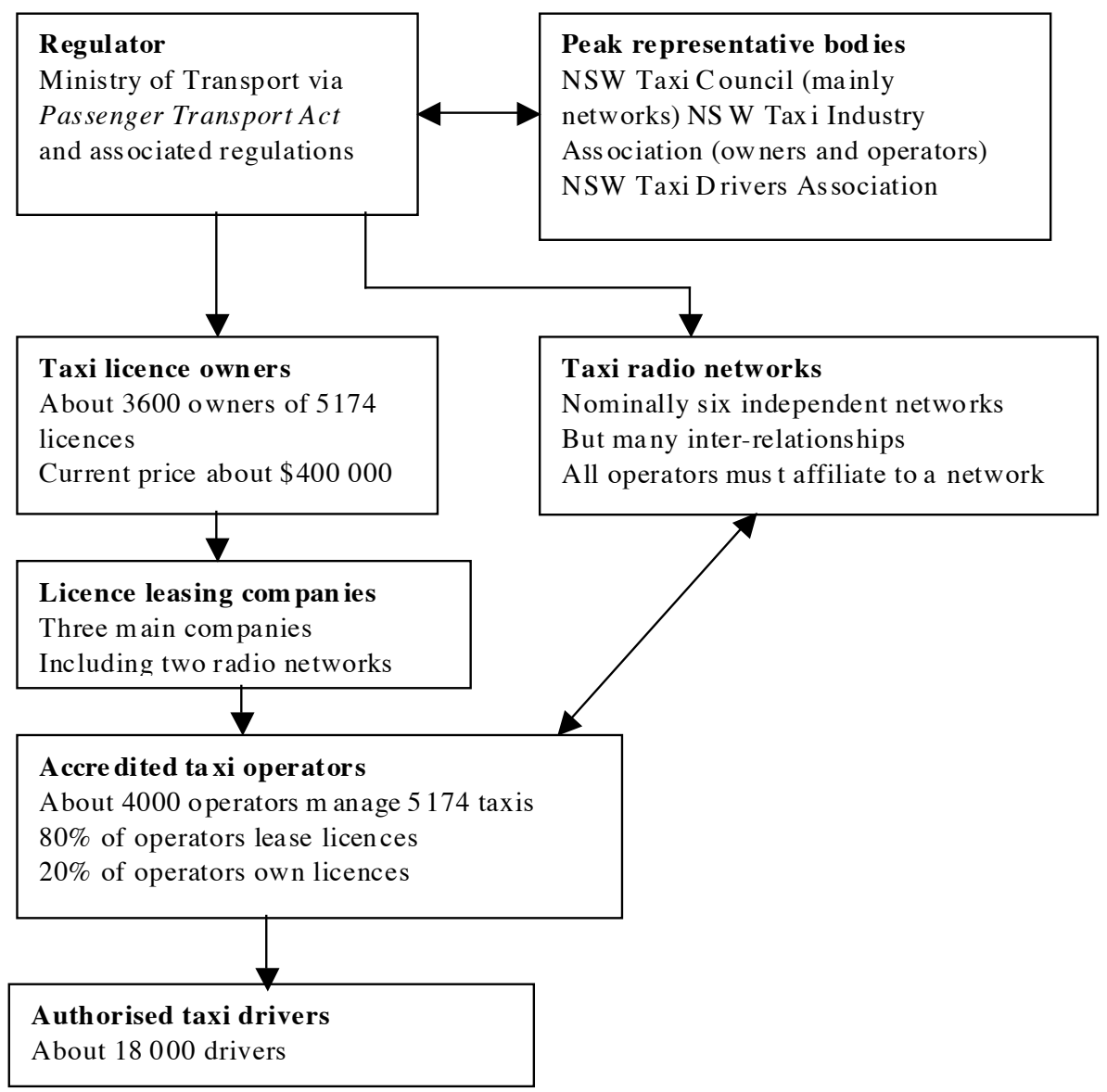

There are direct management and financial relations between the three largest radio network companies. The managing director of the parent entity (Adelhill Limited) of Premier Cabs holds over a million shares in Cabcharge, has been a director of Cabcharge since 1996, and draws an annual salary of some $\$ 100$ 000 from Cabcharge (Cabcharge, Annual Report, 2007-08). Cumberland Cabs Company Pty. Ltd., a subsidiary of Premier Cabs, owns over a million shares in Cabcharge. Legion Cabs (Trading) Cooperative Society Limited owns 2.75 million shares in Cabcharge. In addition, nearly all taxis are fitted with Cabcharge's EFTPOS facility for which Cabcharge charges 11 per cent of the fare (GST inclusive).

Drawing on Cook (2005) and allowing for some growth, there are about 19000 authorised taxi drivers in Sydney. The taxi drivers pay operators between $\$ 120$ and \$200 per shift depending on the time of the day and week. They also pay fuel costs. 
In summary, the Cabcharge, Premier and Legion taxi radio networks control over 90 per cent of the taxi operators and taxis in Sydney, with the latter two networks having a strong allegiance to Cabcharge. This virtual monopoly is made possible because the government regulates that all operators must affiliate with an established network. ${ }^{4}$

\section{Major regulations of the Sydney taxi industry}

There are four main forms of regulation on the taxi industry: regulations of quantity (or entry), industry structure, services and prices.

\section{Quantity (entry) regulations}

The Ministry of Transport and Infrastructure (MTI) has always restricted the number of taxi plates either by offering a limited number to the market or by offering plates at uncompetitive prices compared to buying or leasing secondary market licences. Consequently the uptake of new licences has averaged only 1 per cent per annum and these have been mainly wheelchair-accessible taxis (MTI 2010a).

Drawing on various sources, an estimated 1300 plates have been issued since 1990. This represents an increase in the taxi stock of about 33 per cent over 20 years; that is, an average growth rate of 1.4 per cent per annum inclusive of new WAT licences. On the other hand, between 1991-92 and 2008-09, real gross state income rose by 85 per cent, which was equivalent to 3.8 per cent per annum..$^{5}$ Allowing an income elasticity of demand for taxi services of 1.0, demand for taxi services would have risen likewise by 85 per cent between 1991 and 2009. Consequently the price of a taxi licence rose from $\$ 150000$ in 1990 to over $\$ 400000$ in late 2009, a real price rise of some 66 per cent (MTI 2010b). Effectively the capitalised monopoly rents exceed $\$ 2.0$ billion.

Late in 2009, the government announced that it would auction a limited number of 10-year licences. For financial year 2010-11, it would auction 167 new 10year licences, which is only about a 3 per cent increase in the stock. This has no impact on excess demand. According to AMB Taxi Brokers, by November 2010 the price for a taxi plate had risen to $\$ 425000$ (www.ambtaxi.com.au).

\footnotetext{
4 The list of owners of taxi plates is not publicly available, but it is thought that the networks own only a small proportion of the plates.

5 ABS Cat. No. 5220.0, Australian National Accounts: State Accounts, Table 1.
} 


\section{Regulation of industry structure}

In the NSW regulatory structure, the radio networks are both major industry player and industry monitor. In effect, the regulations empower the networks to control all operators and drivers in Sydney. As outlined by the MTI (2008), this document:

forms part of the regulatory framework within which network providers are to provide clean, safe and reliable taxi services to the travelling public.... The provision of these services is achieved through a complex set of regulatory mechanisms that reflects the structure of the NSW Taxi Industry and provides clarity on the taxi-cab network provider's accountabilities, include (sic) how these accountabilities are to be appropriately cascaded down through to taxi cab operators and drivers. In this regard, the taxi-cab network provider is considered to be the principal entity for taxi-cab services. (italics added)

Accordingly, taxi operators are required to:

- be affiliated with a taxi network for the provision of booking services,

- fit taxis with a network receiver and prescribed communication and safety devices, and

- ensure that all taxis are fitted with the decals of the network and painted in the colours of the network.

Taxi drivers are required at all times to:

wear the approved uniform of the network to which the taxi is connected,

- use the taxi's receiver in accordance with network procedures,

- observe the published rules and by-laws of the networks, and

- comply with all reasonable requests of the network with respect to passenger services.

Taxi drivers are prohibited from soliciting for work and from using unauthorised trunk radio devices to coordinate work with, or to pass work on to, other taxi drivers. ${ }^{6}$

To obtain a taxi network authorisation, an applicant must satisfy the DirectorGeneral of Transport that 'the applicant has the ability and willingness to discipline any user of the network who fails to meet the standards or comply with the rules'. (www.transport.nsw.gov.au. Emphasis added).

6 NSW Passenger Transport Regulation 2007, clause 147. 
The key standards that the networks are expected to meet relate only to booked services. The networks are expected to meet at least 97 per cent of all booked requests over a month and to pick up at least 85 per cent of intending passengers with a waiting time of no more than 15 minutes and 98 per cent of passengers with a waiting time of no more than 30 minutes. These standards relate to the whole area of Sydney, but networks can offload to another network with a formal written agreement between the two networks.

\section{Service regulations}

Numerous regulations apply to each segment of the taxi market. ${ }^{7}$ The following three regulations have significant impacts on industry operations.

- All taxis must be large enough to carry at least four adult passengers and be less than six years old. The size requirement restricts the type of vehicle that may be used and increases unit costs.

- A taxi driver must accept a hiring immediately when offered whatever the destination within the Sydney metropolitan area. Taxi drivers are not allowed to specialise in services in particular areas or to particular clients. This contravenes the fundamental economic concept of gains from specialisation of services. As a taxi driver observed to the writer: 'Taxi drivers have very limited capacity to plan and optimise their schedule.'

- Taxis cannot display a destination sign except in very limited circumstances. This restricts the opportunity for multiple hiring. Indeed, multi-hiring en route is proscribed.

\section{Price regulations}

The MTI (on the advice of the Independent Pricing and Regulatory Tribunal, IPART) sets fare structures and maximum fares. The fares include a flag-fall fare, distance and time charges, a night-time surcharge and booking fees. Road tolls and EFTPOS charges are added to the fares. The set fares include costs of taxi licences and are designed to ensure a full return on capital and labour for all participants in the taxi industry. However, IPART does not regulate the network fees to operators or Cabcharge's 11 per cent EFTPOS fee (GST inclusive), which is a monopolistic charge.

The fares do not distinguish between peak and off-peak periods, although there is significant excess demand for taxis in peak hours and excess supply in offpeak hours. At the request of the NSW Taxi Council, the peak industry body controlled by the networks, IPART (2008) recommended that a higher fee (up to $\$ 11$ extra) could be charged for premium services on condition that the taxi must

7 See Passenger Transport (Taxi-cab) Services Regulation 2001 and the Passenger Transport Regulation 2007. 
be booked through a network and that the networks must offer a standard service at the regulated standard fee at the same time. It is not clear how premium services would be defined or how such a scheme would work.

In an attempt to protect the net income of taxi drivers, the NSW Office of Industrial Relations sets the maximum rates that drivers pay per shift to operators. These rates vary by time of day and week. These regulated rates appear to be mostly above market rates and so are not applicable; but if a driver wishes to hire a taxi at the most profitable time (Friday evening) he or she may have to agree to drive at a less profitable time (such as Monday evening). Immediately the fares increase on 1 July each year, so do driver pay-in rates.

\section{Performance of the Sydney taxi industry}

To discuss performance standards, I draw on four sources. First, the Cook (2005) Inquiry into the industry was highly critical of network controls over taxi operators and drivers and their consequence for consumers: 'Over a very long time the regulatory framework has become distorted. It has protected the interests of established industry players while becoming punitive and ineffective in managing customer service.' The inquiry argued that the prime objective of the networks is to extract income and economic rents out of the operators. Only one in six services is a network-booked service. The rest are hailed off the street or taxi rank. The networks do not provide customer taxi services and have only indirect concern for the quality of the consumer service. In the words of a taxi operator interviewed by the writer: 'There is a cancer at the heart of the taxi industry. The control of the networks has eroded responsibility and reward for providing a quality taxi service'.

Second, IPART (2009) provides data on some key performance indicators for taxi booking services. As shown in Table 1, taxis pick up only 69 per cent of the passengers requesting bookings. However, an unknown number of unmet requests are due to customer cancellations or no-shows.

Table 2 shows waiting times for phone bookings based on network data. For passengers picked up, the waiting times are within regulated standards. However, these data are of doubtful value if many requests are not met. More fundamentally, bookings requested are not equivalent to bookings required. An unknown number of people do not book taxis in peak hours because the services are not reliable. This reduces further the utility of timeliness claims. 
Agenda, Volume 17, Number 2, 2010

Table 1: Bookings and pick-ups in 2008-09 (excluding WATs)

\begin{tabular}{lll}
\hline Measure & No. & $\%$ \\
\hline Number of bookings requested ('000) & 12736 & \\
Number of jobs accepted by taxi drivers & 10100 & 79.3 \\
Total pick-ups & 8752 & 68.7 \\
\hline
\end{tabular}

Source: IPART 2009.

Table 2: Pick-up times as \% of total pick-ups made and bookings requested

\begin{tabular}{llllll}
\hline & $\begin{array}{l}<15 \\
\text { minutes }\end{array}$ & $\begin{array}{l}\mathbf{1 5 - 3 0} \\
\text { minutes }\end{array}$ & $\begin{array}{l}\mathbf{3 0 - 6 0} \\
\text { minutes }\end{array}$ & $\begin{array}{l}>60 \\
\text { minutes }\end{array}$ & Other \\
\hline All pick-ups & $92.9 \%$ & $6.3 \%$ & $0.8 \%$ & $0.0 \%$ & $\mathrm{n} / \mathrm{a}$ \\
Bookings requested & $63.8 \%$ & $4.3 \%$ & $0.5 \%$ & $0.0 \%$ & $31.3 \%$ \\
\hline
\end{tabular}

Source: IPART 2009.

The third source on performance is the Colmar Brunton (2003) survey of 1347 taxi users across Australia, including 302 taxi users in Sydney. The following are the main results.

- Of all Australian cities, Sydney recorded the lowest scores for taxi trip satisfaction.

- Thirty-eight per cent of respondents in inner Sydney and 22 per cent of respondents in outer Sydney had tried to get a taxi in the last six months and failed.

- About 5 per cent of respondents in Sydney had made a complaint to a taxirelated agency but four times that many had felt like complaining and did not do so.

Network-generated records of complaints (which are reported by IPART) are incomplete records of industry performance because many potential complainants do not bother to make a complaint.

The Australian Tourism and Transport Forum survey of Taxi Standards in Australian Cities in December 2009 (see www.ttf.org.au) provides a fourth source on performance. Over half the respondents were based in Sydney. Threequarters of respondents regarded taxi services as poor or very poor in Australian cities and Sydney was rated the worst city. Ninety per cent of respondents said that reform of the taxi licensing scheme should be explored. 


\section{The taxi industry in other Australian cities}

Most Australian cities share many features of the Sydney taxi industry. These include highly regulated entry and high licence plate prices (over \$400 000 in Melbourne), requirements that operators must affiliate with a taxi radio network, the dominant role of the network(s) in the industry, the ubiquitous Cabcharge 11 per cent add-on for EFTPOS payments, close company relationships and high market shares for one or a few taxi companies in the city (Swan Taxis in Perth, Aerial in Canberra, Black and White Cabs and Yellow Cabs in Brisbane).

\section{Policy Objectives and Market Regulation}

Policy objectives are often defined vaguely as the 'public benefit' (Nicholls 2003). Here I follow the standard economic classification of efficiency and equity (or social) objectives but also consider an objective that is sometimes proposed for public transport; namely, 'universal' or equal access. ${ }^{8}$

\section{Efficiency objectives}

A market is efficient when firms supply the services that people want at least cost. It is inefficient when people are willing to pay for a service but it is not provided. It is well established that competitive markets produce these efficient outcomes (Abelson 2008).

We should note here that the taxi market may be viewed as three markets (cruising, rank and booked markets) with distinct features. There are also separate markets for taxi radio networks (or communications), operators and drivers. Most of these markets meet most requirements of a competitive market. They provide excludable private goods. There are few economic barriers to entry to and exit from the industry and, without regulation, most parts of the market would be competitive.

The economics literature identifies some potentially significant market failures in taxi markets, including imperfect competition, information failures and the interaction of demand and supply. Imperfect competition arises when there are significant fixed costs and average costs fall with size of operation. This

8 In hearings of the NSW Legislative Council Select Committee on the NSW Taxi Industry (20 February 2010), members of the Select Committee asked the author, who was giving evidence to the Committee, how deregulation of the taxi industry could achieve 'universal access' to taxis. This was clearly a perceived political objective. 
phenomenon could conceivably apply to taxi radio networks. However, given the many potential suppliers of communications equipment, it is questionable whether there are major cost barriers to provision of radio network services.

Taxi-cab operations may also experience falling average cost. Many costs per shift are fixed and the marginal cost per trip is below average cost. The key concern is that an increase in taxis may increase idle time and reduce utilisation per taxi. If demand for a taxi's services falls from $D_{1}$ to $D_{2}$, as in Figure 2, trips per shift fall from $Q_{1}$ to $Q_{2}$ and average cost rises. ${ }^{9}$ Liston-Heyes and ListonHeyes (2007) argue that this implies that that entry restriction would minimise unit costs.

\section{Figure 2: Rising average cost with declining taxi utilisation}

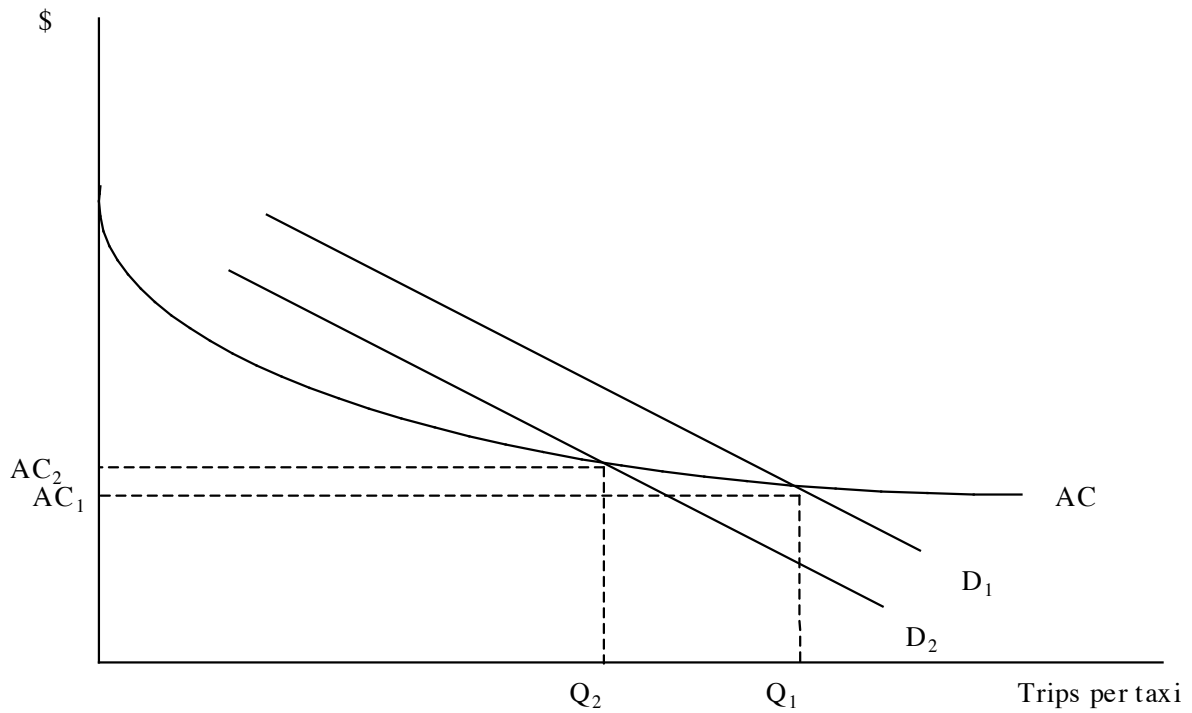

However, there are three offsetting factors. First, increased capacity provides an offsetting benefit by reducing passenger waiting time, which in turn increases the demand for taxi services. Second, if artificial imposts, such as fees for taxi plates, are abolished, in a price-regulated market like Sydney's the fares will fall and demand for taxi trips will increase at no cost to taxi drivers. Third, in a deregulated market, taxi drivers with spare time in off-peak hours may obtain income from alternative work such as community transport or courier work or even work outside the transport sector.

9 Note that the demand curves in Figure 2 are downward-sloping, indicating minor locational differentiation of product in the hailing market. But the same result follows with horizontal demand curves. 
Lack of information or, more precisely, asymmetric information, is another potential market failure. Taxi users may not know the quality of their taxi vehicle or driver, although in a competitive market operators would have an incentive to create a reputation of service. There is certainly a case for regulating safe standards for vehicles and drivers. However, safety issues are generally tackled most efficiently by testing vehicles and training and testing drivers rather than by suppressing trade.

In relation to price information, the main problems arise in the hailing market rather than in the rank or booking services. In the latter markets, comparative prices are easier to obtain. ${ }^{10}$ In the hailing market, taxis have a spatial monopoly and there can be significant search costs. Then, monopoly pricing can occur even with a large number of prospective (deregulated) suppliers (Diamond 1971). Another predicted consequence of uninformed consumers in a deregulated hailing market is decline in service quality.

However, these conclusions assume that consumers are poorly informed about service quality and prices. It is increasingly possible for anybody to access comparative price information at any time on the Internet, even in the hailing market. Price information deficits can be dealt with by requiring taxis operators to post fares and/or indicative trip prices and other relevant service information on a common public website as well as in taxis.

Another efficiency issue is the inter-relationship between demand and supply. Demand is a function of fares and customer waiting time (and therefore of the supply of taxis). The supply of taxi services depends in turn on taxi fares and costs and on driver waiting time (and therefore on the demand for taxis). Some theorists (Cairns and Liston 1996; Liston-Heyes and Liston-Heyes 2007) have observed that this interaction between demand and supply can produce more than one equilibrium (output) solution in the market and that one equilibrium may be preferred on welfare grounds to another. In principle, this could justify some regulation. However, the practical implications are far from clear. It would be asking a lot of an industry regulator to adjust industry settings because of a market failure to achieve the preferred welfare-maximising equilibrium.

In summary, economic principles suggest that competition would improve services in the taxi industry. Information failures justify regulating vehicles and drivers for safety issues. Other market failures provide little justification for substantive regulation of the industry.

Notwithstanding these arguments, some analysts have concluded that deregulation of taxi markets has had adverse consequences (Teal and Berglund 1987; Dempsey 1996; Toner 1996). Bekken (2007) produced a balanced and

10 However, this may cause problems in congested areas such as airports. 
more up-to-date summary for European countries which was accepted by OECD (2007). Bekken found that removal of entry restrictions significantly reduces waiting times. Their removal may not reduce fares because fares are often inefficiently depressed (especially in peak hours) under a regulated regime. Also, unit costs may rise because of lower utilisation in low-demand areas. And, almost always, deregulation produces more fare and service variations. When entry is deregulated but fares remain regulated, servicing of profitable areas tends to increase and servicing of less-profitable areas to fall. Also, vehicle or driver standards have fallen in some places, but this may reflect inappropriate relaxation of regulations rather than unrestricted entry.

The conclusion is that an efficient policy package is required. Deregulation of entry needs to be combined with deregulation of industry structure and service rules and possibly price deregulation, but with continued regulation of basic taxi and driver standards.

\section{Equity objectives}

There are many possible equity objectives. They may include protecting consumers generally or by area or by type of user such as those who need wheelchair access. Price regulation or cross-price subsidies may protect consumers albeit at a potential loss of competition and services for some consumers.

Government may also aim to protect one or more of the industry supplier groups. Restrictions on entry protect existing owners of capital, but discriminate against new entrants. Entry restrictions may also be viewed as supporting incomes of existing taxi drivers but, as will be seen below, this is an illusion.

Current price regulations in Sydney are presumably designed to protect consumers against higher prices as well as to increase wheelchair-assisted services. They are also designed to protect owners of taxi plates. Undoubtedly, the regulations also assist the taxi radio networks but this may be a by-product of policy rather than an objective.

A broader interpretation of the regulations in Sydney is that the government views taxis as a form of public transport, and regulates the industry with the objective of providing households across the city with universal or equal access to taxis services with only short waiting times This was a major concern of some members of the Select Committee of the NSW Legislative Council Inquiry into 
the taxi industry. To achieve this objective, the government gives the networks powers to direct taxi drivers to take any jobs that arise in a prescribed area along with performance requirements for the networks.

\section{Universal or equal access for taxi services}

There are five questions to be answered with respect to the universal-access objective. $^{11}$

- What does the principle of universal or equal access for taxi services mean?

- Is this a reasonable principle?

- Does the present regulatory regime for taxi services provide approximately universal or equal access?

- Can a regulated regime provide universal or equal access?

- Would deregulation provide more universal or more equal access?

What does the principle of universal or equal access to taxi services mean?

A starting definition of universal or equal access could be that all members of a community would have similar levels of access, defined perhaps as waiting times, and pay similar fares for a basic and safe taxi service. This definition would presumably allow fares to vary with distance and by time of day or night. This would allow discrimination against people who want to travel long distances or at night.

However, 'community' and 'basic service' need to be defined. Presumably, the principles apply to people within a defined urban area. Thus all people within Sydney should have equal access, but all people in Coffs Harbour could have a different level of access. Would a 'basic service' involve an average waiting time of 10 or, say, 15 minutes?

Is the principle of universal or equal access for taxi services reasonable?

The principle of universal or equal access for taxi services (or indeed to other public-transport services) sounds reasonable, but there are strong reasons why it may be accepted only with qualifications.

First, demand and supply conditions may vary greatly within an urban area. In areas of low population or employment density, the cost per taxi trip is likely to be higher because of greater driver waiting time. If a household locates in

11 These questions do not deal with the special case of wheelchair-accessible taxis, which raises further issues. 
an area where taxi costs are high, they cannot expect levels of service or prices similar to those in an area where taxi costs are low. Presumably, equality of access should be qualified by some consideration of costs.

Second, it is questionable whether public-transport disadvantage is a separate category of household disadvantage. Households on any given level of income can choose less housing and better public transport or more housing and less public transport. Certainly the latter group has chosen less public transport, but the two households have equal real income. Of course income-disadvantaged households have less of both housing and public transport. But the underlying disadvantage is income, rather than transport. A policy that addresses transport disadvantage separately is horizontally inequitable: it is not treating like households in a like way.

Does the present regulatory regime for taxi services actually provide (approximately) universal or equal access?

The current regulatory regime in Sydney does not provide universal or equal access. There are numerous examples of taxi drivers selecting their passengers and ignoring those that are less-profitable or unwanted. IPART (2009) reported that in 2008-09 taxi drivers rejected 34.6 million booking requests from radio networks and accepted only 10.1 million jobs. For each job accepted taxi drivers turned down three jobs, although they presumably had no passenger at that time. The full reasons are not known. Media stories suggest that it is far harder to get a taxi in outer suburban areas than in inner-city areas. And it is well known that taxi drivers routinely drive around at night with doors locked and windows virtually closed, and select passengers to preferred destinations, often turning down requests for short trips. This selection of passengers is inconsistent with the principle of universal or equal access.

\section{Is it possible for a regulated regime to provide universal or equal} access?

The lack of access for some people is directly related to the regulated nature of the industry.

The lack of access to taxis that people in Sydney experience reflects three related factors: barriers to entry due to the licence fee and the prohibition on independent businesses; the excess demand for taxi services in peak hours; and price regulations that do not reflect the real costs of taxi operations.

The barriers to setting up a taxi business restrict the services supplied to lower-demand areas of Sydney. They also create the excess demand for taxis in virtually all areas in peak hours. The regulation of prices makes long taxi trips 
more profitable than short ones. When there is excess demand, or even when there is a choice of passengers at other times, taxi drivers try to choose the moreprofitable trip.

Thus the lack of access for some people is directly related to the regulated nature of the industry. The regulation that requires taxi radio networks to serve the whole metropolitan area within 15 minutes, even with off-loading to another network, is ineffective and unrealistic. In any case, booked services represent only 16 per cent of all taxi trips.

Could industry regulations be redesigned to ensure equal access? It is hard to see how this can be done. There are limits to the extent that a regulator can order taxi operators or drivers to provide an unprofitable service. So long as entry is restricted and fares are regulated, taxi services will not be universal. Taxi drivers will attempt to select the most profitable passenger(s) and discriminate against the others. Indeed, fare regulations alone would cause taxi drivers to refuse some demands for trips for which passengers would be willing to pay but cannot do so under the maximum fare regulation.

\section{Would deregulation provide more universal or more equal access?}

OECD (2007) concludes that deregulation of entry and industry structure provides more widespread and universal services. Given the level of excess demand for taxi services at present, as evidenced by the size of the licence fee, complete deregulation of entry would probably increase taxi services by at least 20 per cent to 30 per cent in two to three years (Abelson 2010). The market would be far more competitive and driven by user demands.

If, as part of a reform package, fares were deregulated but publicly advertised, fares would tend to reflect taxi costs. This could increase prices for some groups; for example, elderly people who travel short distances. But this would enhance access in that taxi drivers would not discriminate against these groups. However, if equal access is defined as equality of fares across all trips, greater fare variations would be regarded, by definition, as less equal access.

\section{Evaluating the Costs and Benefits of Taxi Deregulation}

This section evaluates the net benefits of free entry into the industry subject to operators and drivers passing basic safety checks. Entry deregulation would doubtless produce higher benefits if accompanied by other deregulatory policies, including allowing taxi operators to choose type of taxi vehicle and communication system and to operate as independent competitive businesses. 
Prices could be set competitively and vary by time and place subject to publication on a common website. The extra competition could generate an array of new services and prices and cost savings (see Swan 1979). The evaluation assumes that the networks could not use their quasi-monopoly power to thwart free entry. However, these complementary deregulatory policies are not formally defined or assessed in this evaluation.

\section{Evaluation principles}

Following standard economic principles, any departure from a competitive equilibrium is likely to waste economic welfare (create 'deadweight loss') and moves to a competitive equilibrium to provide an equivalent economic gain. These principles are developed in the four figures below. Figure 3 shows two perfectly elastic supply schedules. With initial supply $\left(\mathrm{S}_{1}\right)$, the fare $\left(\mathrm{F}_{1}\right)$ is the average cost (AC) of a taxi trip plus the licence fee (LF). The demand for taxi trips is given by schedule $\mathrm{D}_{1}$ and there are $\mathrm{Q}_{1}$ taxi trips per period. With no licence fee, the fare falls to $\mathrm{F}_{2}$. Also, the demand curve shifts right to $\mathrm{D}_{2}$ as more taxis enter the market and customer waiting times fall. The fall in fares for existing consumers is a transfer from taxi suppliers to users. However, existing users also gain surpluses equal to area A due to lower waiting times. New users gain consumer surpluses equal to areas $\mathrm{B}+\mathrm{C}+\mathrm{D}$.

\section{Figure 3: User benefits from increase in taxi services and lower fares}

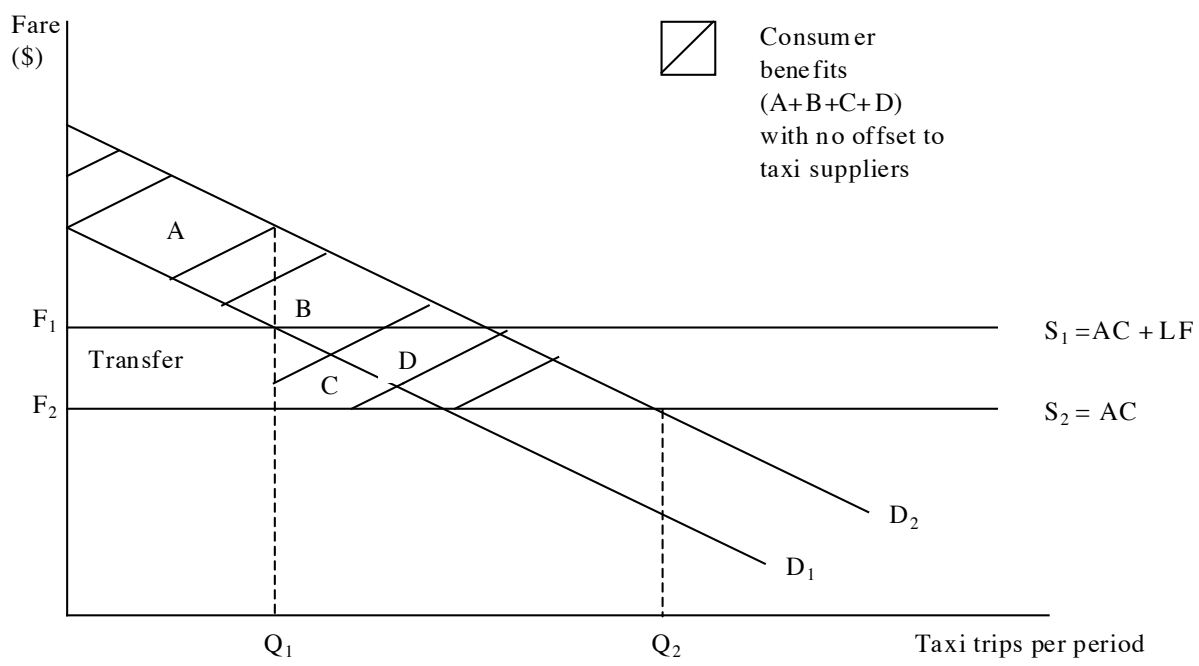

Figure 4 provides an equivalent exposition, drawing on the concept of generalised cost (GC) that is often employed in transport economics. This 
facilitates quantitative estimates. The demand for taxi trips is shown as a function of GC which is the sum of the fare and the user cost of waiting time. In this figure:

$\mathrm{GC}_{1}=\mathrm{AC}+\mathrm{NW}$, where NW is normal waiting time (i.e. average waiting time with no entry restrictions).

$\mathrm{GC}_{2}=\mathrm{AC}+\mathrm{NW}+\mathrm{LF}$.

$\mathrm{GC}_{3}=\mathrm{AC}+\mathrm{NW}+\mathrm{LF}+\mathrm{EW}$, where EW is excess waiting time.

In Figure $4, Q_{R}$ is the number of taxi trips with restricted entry and $Q_{U}$ the trips with unrestricted entry. With unrestricted entry, there is no excess waiting time or licence fee and generalised cost falls from $\mathrm{GC}_{3}$ to $\mathrm{GC}_{1}$.

Figure 4: Basic economic benefits: alternative exposition

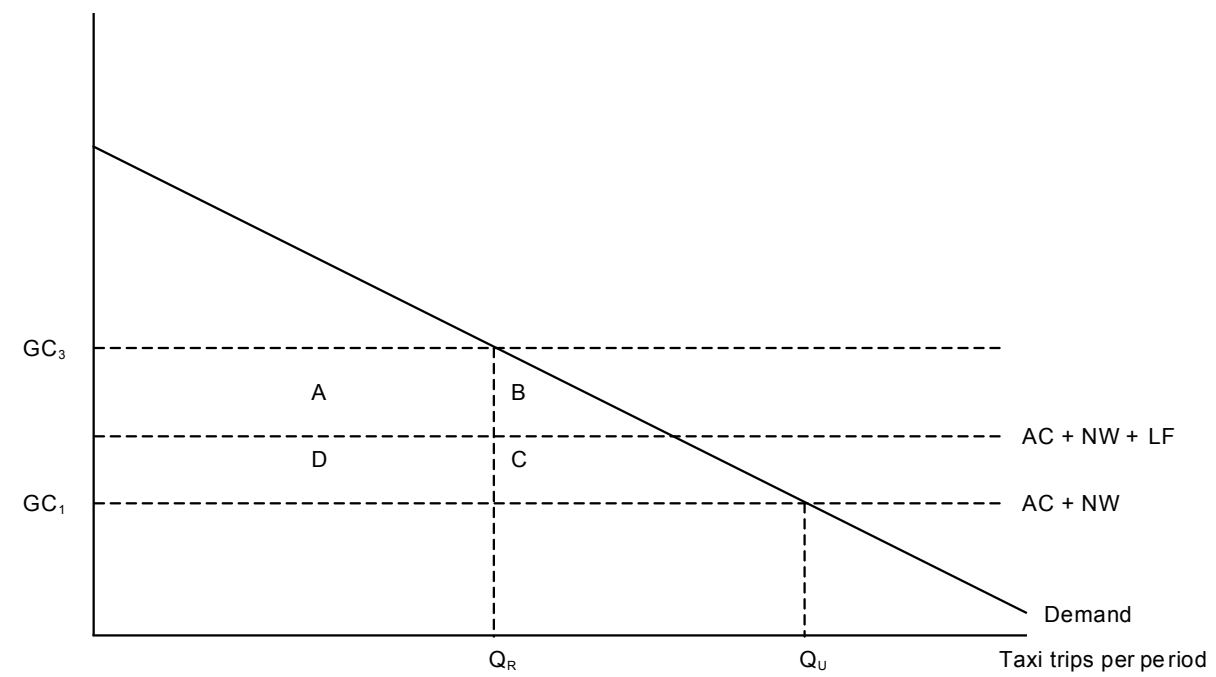

The gross benefits of deregulation to existing taxi consumers equal areas (A + $\mathrm{D})$. The benefits to new users are areas $(\mathrm{B}+\mathrm{C})$. Thus gross user benefit $=\mathrm{A}+$ $\mathrm{B}+\mathrm{C}+\mathrm{D}$. However, the fall in taxi fares associated with area D is a loss to taxi owners. Thus the net social benefit equals areas $(A+B+C)$.

Figure 5 introduces two complications. First, the observed number of trips $\left(\mathrm{Q}_{\mathrm{R}}\right)$ at $\mathrm{GC}_{3}$ in Figure 4 does not represent the true demand for taxis at this price. Many people do not use taxis in peak hours because actual waiting time may substantially exceed mean waiting time or indeed because no taxi may be available at the required time. That $\mathrm{GC}_{3}$ is not an equilibrium price is evidenced by IPART agreeing with a Taxi Council proposal that a premium of up to \$11 on the fare be allowed for undefined 'premium' services. This indicates that real 
demand exceeds observed usage. This is reflected in the $\mathrm{D}_{2}$ demand curve in Figure 5. Given this demand and a deregulated generalised cost of $\mathrm{GC}_{1}$, usage would now rise to $\mathrm{Q}_{U}{ }^{*}$.

Second, the social cost of a taxi trip differs from average (private) cost. The private cost includes indirect taxes (excise taxes and GST) and road tolls, which are transfer payments and not resource costs. On the other hand, taxi trips have some negative externalities (notably traffic congestion and air-quality effects). Given that the estimated indirect taxes exceed the negative externalities (see below), the long-run marginal social cost inclusive of externalities (LRMSC) + $\mathrm{NW}$ line is drawn below the $\mathrm{AC}+\mathrm{NW}$ line. It is assumed that fares must overall cover long-run marginal cost.

In Figure 5, the benefits of deregulation to existing taxi users still equal areas $(\mathrm{A}+\mathrm{D})$. Discounting the loss to taxi suppliers, the net social benefit remains area A. However, the benefits of generated trips are now greater. The benefits to users equal areas $(B+C+E+F+G)$. The other net benefits to society equal areas $(\mathrm{H}+\mathrm{J})$. This is the excess of government revenue and road tolls over the environmental costs of taxi trips.

\section{Figure 5: Adding evaluation complications}

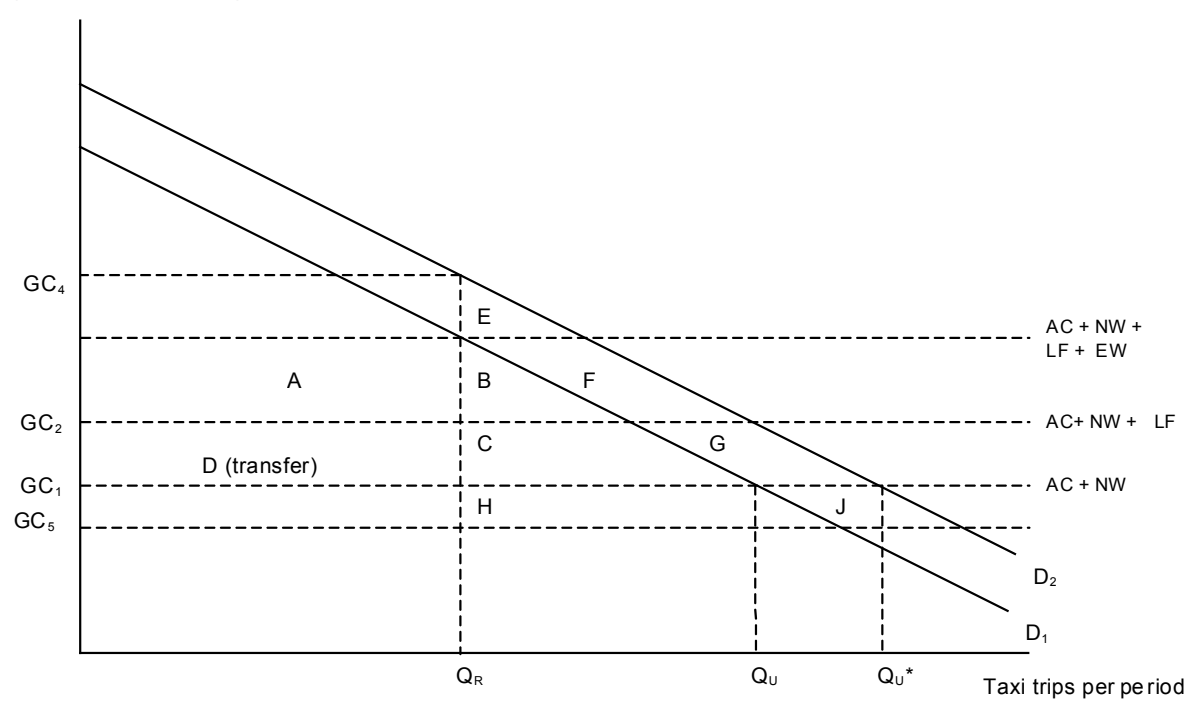

Finally, we introduce differential pricing in peak and off-peak hours. With unregulated pricing, peak fares would likely exceed average unit cost in peak hours so as to equate supply with peak demand. In off-peak hours, fares would be closer to marginal operating cost. 


\section{Figure 6: An off-peak model}

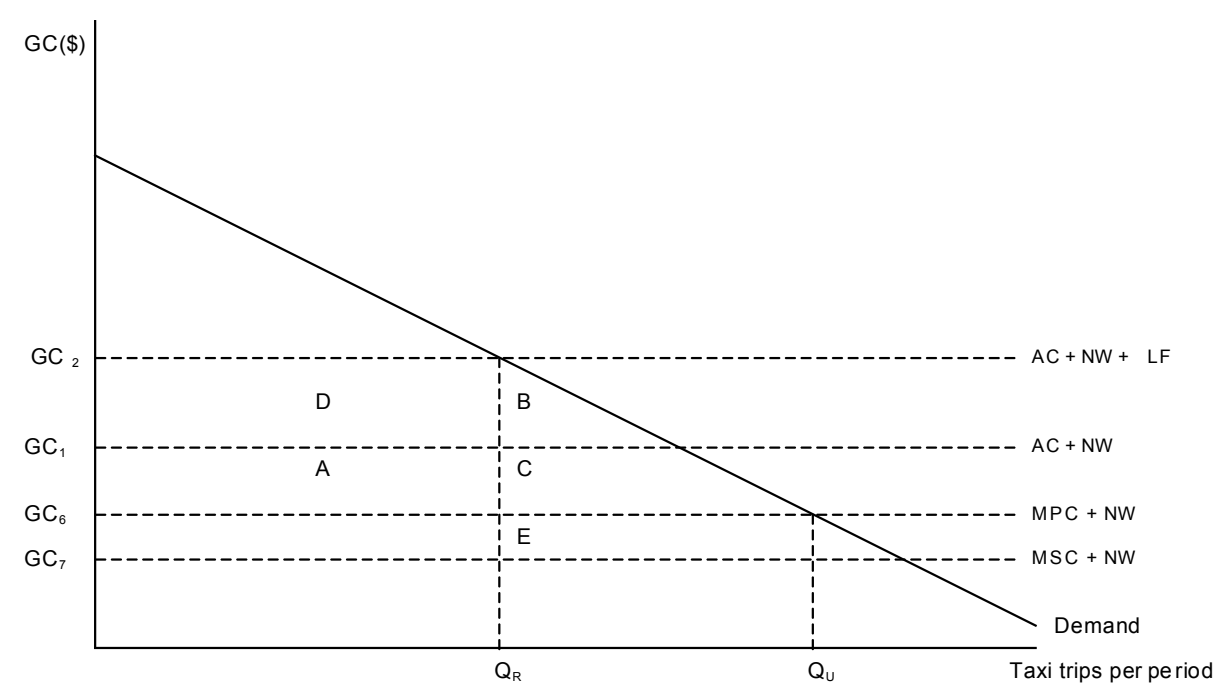

Figure 6 depicts an off-peak scenario. Demand is lower and it is assumed that there is no excess waiting time. It is also assumed that fares will fall, as the private marginal cost (PMC) of operating in off-peak hours does not include fixed vehicle costs. Thus $\mathrm{GC}_{6}$ is lower than $\mathrm{GC}_{1}$ and taxi use $\left(\mathrm{Q}_{\mathrm{U}}\right)$ is determined by the intersection of the demand curve with $\mathrm{GC}_{6}$. Again, marginal social cost (MSC) is lower than PMC.

In this off-peak model, existing taxi consumers gain benefits equal to areas (A + D). However, in this case both areas $\mathrm{A}$ and $\mathrm{D}$ are offset by losses to taxi drivers (who make higher returns in the peak periods). On the other hand, benefits to new consumers equal areas $(B+C)$. Net social benefits equal area $E$.

In the evaluation below, peak-hour effects are evaluated based on Figure 5 assuming that the fare will remain at AC + LF. Off-peak hour effects are based on Figure 6. Based on discussions with taxi drivers, peak hours constitute a third of operating hours per week (40 of the working 120 hours) and taxis do twice as many paid trips in a peak hour as in an off-peak hour. This implies that peak hours account for half of all existing trips in Sydney (30 million per annum) and off-peak hours for the other half (also 30 million trips per annum). 


\section{Estimated Net Benefits of Taxi Deregulation in Sydney}

For the evaluation of taxi deregulation, estimates are needed of taxi trip costs, fares and waiting time in peak and off-peak periods, a peak-period equilibrium fare, social costs and benefits, and the elasticity of demand with respect to generalised costs. The detailed data and estimates (based on 2007-08 data and prices) are shown in the Appendix. I comment here briefly on the basis for these estimates.

IPART (2008) estimated that the average (producer) cost of a taxi trip in 2008 was $\$ 20.20$ and the cost of the licence fee per trip was $\$ 2.43$. However, in an unregulated market, peak-hour fares would likely be above average cost and off-peak fares below average cost. In the absence of data that would enable modelling of these prices, I assume that taxi drivers would continue to charge LF ( $\$ 2.43$ per trip) in peak hours even though it would no longer be a cost but that off-peak fares would fall by the same amount below average cost. Given equal peak and off-peak trips, this ensures revenue neutrality for taxi operators.

The average waiting time for all phone-booked taxis in 2008 is 8.3 minutes (IPART 2008). For this evaluation, a 'normal wait time' with a deregulated taxi fleet is assumed to average five minutes. This is 3.3 minutes below the average time. Given an equal number of peak and off-peak trips, the average excess wait time in peak hours is therefore 6.6 minutes per taxi (making an average wait of 11.6 minutes in peak hours).

Waiting time is usually related to income. The average weekly income in 2008 was $\$ 1145$ (ABS 6302.0). This equals $\$ 30.5$ an hour for a 37.5 hour week. Invehicle leisure time is usually valued at 33 per cent of hourly wage, but waiting time is valued at up to twice this amount (UK Department for Transport 2010). This suggests that non-working waiting time for taxis would be valued at \$20 per hour per passenger. However, working time is usually valued at the wage rate. For business users of taxis this may be above the national average wage rate, so we allow $\$ 40$ an hour. Allowing for two-thirds leisure and one-third business users, the weighted average could be $(0.67 \times \$ 20)+(0.33 \times \$ 40)=\$ 27$ per hour.

Allowing for 1.8 passengers per taxi, this would be $\$ 48.6$ per hour or $\$ 0.81$ per minute. Thus the average cost of five minutes waiting is $\$ 4.0$ per taxi. The cost of 11.6 minutes waiting is $\$ 9.3$ per taxi.

Estimating the market clearing price with current regulations $\left(\mathrm{GC}_{4}\right.$ in Figure 5$)$ is also problematic. The taxi industry has argued for an additional $\$ 11$ per trip for 
undefined premium services (presumably in peak hours). For this exercise, the average market clearing price premium in peak hours is assumed conservatively to be half of this (i.e. $\$ 5.50$ per trip).

To estimate the third-party effects, the GST component (\$1.84) of the average fare is taken out of AC. However, environmental and congestion costs are included. ${ }^{12}$ Allowing \$0.10 per vehicle km for these costs@ 7 km per trip, these costs are $\$ 0.70$ per taxi trip.

To estimate generated taxi trips I allow a price elasticity of demand with respect to generalised cost of -1.0 , based on Toner and Mackie (1992) and OXERA (2003). This is an average elasticity. Arguably the elasticity could vary for fares and waiting time and for peak and off-peak hours.

\section{Summary of results}

Table 3 shows estimated benefits and costs of entry deregulation in Sydney. On plausible and quite conservative assumptions about waiting times and other costs, the estimated net gain is $\$ 265$ million per annum. While detailed sensitivity tests have not been attempted, there is no reason to doubt that this estimate represents a reasonable order-of-magnitude estimate of the gain from entry deregulation. Over 20 years, with unchanged demand and supply conditions, this produces a net benefit with a present value of $\$ 2.8$ billion (assuming a real discount rate of 7 per cent per annum, the NSW Treasury recommended discount rate). This is consistent with the estimated capitalisation of rents figure quoted above.

These benefits are based on free entry into the industry and price flexibility. They may require some concurrent reduction in the power of the networks over the industry. As OXERA (2003) reported, total expected benefits of deregulation were not obtained in the United States because the reforms did not address the oligopolistic nature of industry. If taxi operators were free to compete and develop their own competitive brands, there would almost certainly be additional service and productivity gains.

In the distribution of the gains, consumers are estimated to obtain annual benefits of $\$ 295$ million and there would be small gains to government revenue. On the other hand, taxi industry suppliers would lose an estimated \$51 million a year.

12 Arguably, the GST component of the fare should not be included as a benefit to government because government may lose GST on expenditure forgone to make a taxi trip. On the other hand, any excise tax and road tolls associated with generated trips should be included as a benefit to the recipients. These have not been allowed for in these calculations. 
Owners of taxi licences would lose annual licence fees of about \$140 million. But with deregulated pricing, taxi operators are assumed to retain peak-hour fares and so they would gain the LF component of fares in peak hours.

Deregulation of entry into the industry would have two other noteworthy equity effects. First, it would promote employment. Each taxi licence issued creates at least 2.7 equivalent full-time jobs (because taxis are driven about 6000 hours in a year). This assists people (including students and retirees) who want to supply taxi services without having to pay $\$ 12000$ a year for their share of the licence to provide a service. Second, deregulation would assist low-income and elderly people who do not own or cannot drive private vehicles. Taxis play an important role in providing transport to individuals for whom other forms of public transport are not suitable.

\section{Policy Questions}

Given these results and others in the international literature, why have such strong regulations been retained in Sydney and elsewhere in Australia? There seem to be several possible explanations. First, one explanation is that the policymakers have little exposure to economic arguments. This appears to be a strong possibility.

Second, policymakers may believe that the analysis is flawed. Clearly, the estimated benefits of deregulation are based on a large number of inputs and assumptions. There is some international evidence that poorly constructed packages of reforms may be ineffective (Moore and Balaker 2006). Certainly some regulations need to be retained. However, it would be hoped that policymakers would recognise that the underlying theory and evidence are robust and that large gains could be realised from deregulation of the taxi industry. In a wideranging review of international experiences with deregulation, the OECD (2007: 8) concluded that: 'Post-reform evidence generally demonstrates strongly positive results measured against a range of criteria. Substantially increased taxi numbers mean customer waiting times tend to fall substantially, while customer satisfaction levels have also substantially improved'.

Third, policymakers may believe the analysis is incomplete because the reforms would not meet the public transport objective of 'universal and equitable access'. In reviewing this objective, we found that this concept is poorly defined and that competitive markets with light regulation are more likely to achieve general and equitable access than a strongly regulated taxi industry. 


\section{Table 3: Summary of results}

\section{Estimated annual benefits in peak hours}

Existing users lower waiting time (Area A)

New user benefits (Areas $B+E+F$ )

Taxi supplier gains new users (Areas $C+G$ )

New social benefits (Areas $\mathrm{H}+\mathrm{J}$ )

Total benefits

\section{Transfers}

To suppliers: higher peak hour fares

\section{Estimated annual benefits in off-peak hours}

New user benefits (Areas $B+C$ )

New social benefits (Areas $\mathrm{J}+\mathrm{K}$ )

Total benefits

\section{Transfers}

Existing users lower fares (Areas D $+A$ )

\section{Summary results: all users and suppliers}

Gains to taxi users

Gains to taxi suppliers

Social benefits

Total net benefits per annum

Transfers per annum

Supplier gains from higher peak fares

Supplier losses from lower off-peak fares

Net gain to consumers (loss to producers)

\section{$\$ \mathrm{~m}$}

Q existing $\times(G C 3-G C 2) \quad 157.2$

$\mathrm{Q}$ new $\times(G C 4-G C 2) \times 0.5 \quad 49.5$

$\mathrm{O}$ new $\times(\mathrm{GC} 2-\mathrm{GC} 1) \quad 22.3$

$\mathrm{Q}$ new $\times(\mathrm{GC} 1-\mathrm{GC} 4) \quad 10.4$

239.4

Q existing $\times \mathrm{GC} 2-\mathrm{GC} 1$

$\mathrm{Q}$ new $\times(\mathrm{GC} 2-\mathrm{GC} 6) \times 0.5 \quad 14.7$

O new $\times(G C 6-$ GC7) $\quad 11.1$

$\mathrm{Q}$ existing $\times(\mathrm{GC} 2-\mathrm{GC} 6) \quad 146.0$

No offsetting losses

221.3

No offsetting losses

No offsetting losses

265.1

146.0

73.7

295.0

$-51.4$

21.5

265.1 
Fourth, my discussions with regulators suggest that policymakers may favour the NSW type of regulatory structure because it outsources the onerous tasks of monitoring and controlling taxi drivers to a few networks. This minimises in-house administration and responsibility. However, outsourcing regulatory responsibility to the networks makes a major service supplier also an industry regulator. This creates conflicts of interest, inhibits competition and sets up unhealthy relationships between suppliers in the taxi industry. The end result has all the symptoms of regulatory capture. ${ }^{13}$

The fifth, and possibly most common, explanation for opposing reform is that the social costs of deregulation are unacceptable. The major losers from free entry would be investors in taxi licence plates. This small group has a large interest in opposing change compared with the dispersed benefits to taxi users. It is generally accepted that there is no legal requirement to compensate taxiplate holders for any reduction in the value of the plates (Deighton-Smith 2000). The size of compensation, if any, is therefore a political decision. This decision may be informed by evidence about past purchase prices, returns on investments since purchase and hardship issues. If any compensation is considered necessary, it could be at less than current market values.

Be that as it may, several strategies could reduce the cost to government (see also Deighton-Smith 2000; Johnston 2000).

Government may adopt a gradual reform process over, say, 10 to 15 years. This allows plate holders to continue to gain significant income and government to offer lower compensation in the longer term. However, this delays the substantial benefits of taxi reform and risks an about-turn on the reform process.

1. Another strategy for reducing costs to government would be to maintain regulated taxi fares in the peak or even allow them to increase, notwithstanding an increase in taxis. This would soften the fall in value of taxi plates. Taxi users would still be better off on a net basis because of the fall in waiting times in peak hours.

2. The next two strategies are variations on a buy-back strategy. When government buys back a licence, it would lease it out on the market and the lease revenue would partly offset the cost of the buy-back.

13 Some analysts might argue that regulatory capture has not been simply an end-product of outsourcing responsibility for implementing regulations but a result of overly close relationships between the major taxi network company (Cabcharge) and ongoing governments of NSW (see, for example, http://www.smh.com.au/ interactive/2009/taxis/index.html. The chairman of Cabcharge for over a decade has been an ex-premier of the State of NSW and in 2009 the Secretary of the then Ministry of Transport with responsibility for oversight of the taxi industry resigned and took up employment with Cabcharge. However, the author has no evidence of improper behaviour. 
3. Government would buy back all licences at a discounted cost of say $\$ 330$ 000 or less per licence over, say, three years and lease them out at rates falling from $\$ 25000$ towards $\$ 0$ per annum over 10 to 15 years. Government would issue annual increases in licences in line with these falling rates. Plate sales to government would be optional but would be in the owner's interest given the falling lease rates.

4. Another strategy would combine a rights issue with a buy-back. The government would substantially increase the plates in the market by an annual rights issue. In a tested scenario, all existing licence holders receive a 10 per cent increase in their holding, free of charge for four years, and a 3 per cent annual increase thereafter. The plate holders can either sell this entitlement on the market to an amalgamator or sell it back to the government at a discount rate. The government would also buy back full plate licences at a discount to the market. As in strategy (3), the government would lease out plates at a declining annual price.

The net cost to government would depend on scheme detail. However, modelling of these strategies by the author indicates that the net cost to government could be less than $50 \%$ of the cost of full market price buy-back of licences. The cost would be lower if strategy (3) or (4) were combined with maintaining or even increasing peak fares, as in strategy (2). Thus, if compensation is deemed necessary, a combination of (2) and (3) or (4) could substantially reduce the cost to taxpayers while gradually producing considerable benefits of taxi users.

Finally, a brief comment on the impacts of deregulation on taxi drivers is needed. Many taxi drivers oppose any increase in entry apparently because they fear that their already low earnings will be further eroded. However, the monopoly rents accrue to licence holders, not to taxi drivers. Driver income is driven by the demand and supply of drivers. Many long-time Sydney taxi drivers have experienced real falls in income in recent years because the supply of drivers has increased, especially with the influx of immigrants and foreign students. Driver incomes have fallen to a new low equilibrium as drivers compete for work by bidding up pay-in rates. However, as Swan (1979) pointed out, an increase in taxis will increase the demand for taxi drivers, reduce pay-in shift rates and increase take-home earnings. The increase will be positive but small because the driver supply curve is upward-sloping but highly elastic. In addition, the ability of a taxi driver or small group of drivers to establish their own business and brand in a deregulated market could significantly increase driver income. 


\section{Conclusions}

Numerous regulations govern entry, industry structure, service quality and prices for the Sydney taxi industry. Similar regulations are in place in other Australian cities.

However, there are few market failure (efficiency) reasons for regulations other than basic safety regulations. Nor do the regulations achieve a possible publicbenefit objective of universal and equitable access to taxi services across the city.

On plausible assumptions, the net benefits from free entry into the Sydney taxi industry are in the order of $\$ 265$ million per annum. The productivity and service benefits would doubtless be greater if other restrictions on taxi services were lifted, especially the anti-competitive control of the taxi radio networks over taxi operators and drivers.

Although other Australian and international reports have reached similar conclusions, the NSW government (like other Australian governments) resists making reforms. The main reasons for this appear to be a lack of understanding of the benefits of market operations, a policy preference for outsourcing regulation to a few industry players and concerns about the social costs and claims for compensation (although there is no legal basis for compensation). However, the paper also shows that various strategies could achieve reform (and the benefits of reform) and minimise compensation costs.

\section{References}

Abelson, P. 2008, Public Economics, Principles and Practice, 2nd ed., McGrawHill, Sydney.

Abelson, P. 2010, Economics of Taxi Industry Reform in Sydney, Submission No. 30 to the NSW Legislative Council Inquiry into the NSW Taxi Industry. Available at: www.parliament.nsw.gov.au/Prod/parlment/committee.nsf/V3 ListSubmissions?open \&ParentUNID=EA4E5B85CBE5CF0CCA25766B00114 E9A

Bekken, J-T. 2007, 'Experiences with (De-)Regulation in the European Taxi Industry' in OECD, (De)Regulation of the Taxi Industry, Round Table 133, OECD, Paris: 31-58.

Cairns, R. C. and Liston-Heyes, C. 1996, 'Competition and regulation in the taxi industry', Journal of Public Economics 59: 1-15. 
Colmar Brunton 2003, 2002 National Taxi Users Survey Report, prepared for Department of Transport, Western Australia. Available at: www.transport. gov.au

Cook, A. 2005, Ministerial Inquiry into the Taxi Industry, Interim Report. Available at: www.transport.gov.au

Deighton-Smith, R. 2000, Reforming the Taxi Industry in Australia, Staff Discussion Paper, National Competition Council, Melbourne.

Dempsey, P. S. 1996, 'Taxi industry regulation, deregulation and reregulation: an analysis of taxi markets', Transportation Law Journal 24(1): 73-120.

Diamond, P. 1971, 'A model of price adjustment', Journal of Economic Theory 3: 156-68.

Independent Pricing and Regulatory Tribunal (IPART) 2008, 2008 Review of Taxi Fares in NSW, IPART, Sydney.

Independent Pricing and Regulatory Tribunal (IPART) 2009, 2009 Review of Taxi Fares in NSW, IPART, Sydney.

Johnstone, A. 2000, 'Taxi industry reform? Should there be compensation?' Agenda 7: 171-83.

Liston-Heyes, A. and Liston-Heyes, E. 2007, 'Regulation of the Taxi Industry: Some Economic Background' in OECD, (De)Regulation of the Taxi Industry, Round Table 133, OECD, Paris: 91-113.

Ministry of Transport and Infrastructure 2008, Guide for Authorised Taxi-cab Network Providers and Taxi-cab Network Services Standards for the Sydney Metropolitan, Newcastle and Wollongong Transport Districts and the Local Government Areas of Gosford and Wyong. Available at: www.transport.gov.au

Ministry of Transport and Infrastructure 2010a, Release of New Annual Taxi Licences from 1 July 2010.

Ministry of Transport and Infrastructure 2010b, Taxi Licensing Changes for New South Wales.

Moore, A. T and Balaker, T. 2006, 'Do Economists reach a Conclusion on Taxi Deregulation?' Econ Journal Watch 3: 109-32.

National Competition Council 2000, Improving Our Taxis, NCC, Melbourne.

Nicholls, D. 2003, The Role of the Public Interest in the Application of the National Competition Policy to the Australian Taxi Industry, ANU, Canberra. 
OECD 2007, Taxi Services Regulation and Competition, Directorate for Financial and Enterprise Affairs, OECD, Paris.

OXERA 2003, Taxi Markets Literature Review, Annexe G, prepared for the UK Office of Fair Trading, London.

Productivity Commission 1999, Regulation of the Taxi Industry, Commission Research Paper, Ausinfo, Canberra.

Swan, P. 1979, On Buying a Job: the Regulation of Taxicabs in Canberra, Policy Monograph, Centre for Independent Studies, Sydney.

Teal, R. F. and Berglund, M. 1987, 'The impact of taxicab deregulation in the USA', Journal of Transport Economics and Policy XXI(1): 37-56.

Toner, J. P. 1996, 'English experience of deregulation of the taxi industry', Transport Reviews 16(1): 79-94.

Toner, J. P. and Mackie, P. J. 1992, 'The economics of taxicab regulation: a welfare assessment', paper presented to the Sixth World Conference on Transport Research, Lyon.

UK Department for Transport 2010, Values of Time and Operating Costs, Transport Analysis Guidance, TAG Unit 3.5.6, London.

UK Office of Fair Trading 2003, The Regulation of Taxi and PHV Services in the $U K$. 


\section{Appendix: Base data of the Evaluation}

\section{Quantity of taxi trips in Sydney}

Total taxi trips per annum (m) 59.8

Persons per taxi trip

Average trips per taxi per annum

No. of taxis in Sydney

Total shifts per week

Paid taxi trips per shift

Hours per shift

Weeks per year

Operating hours per week

Peak hours Monday to Thursday

Peak hours Friday 9

Peak hours Saturday 7

Total peak hours

Peak hours as \% all business hours

Peak hour/off-peak hour trip ratio

Trips in peak hours as \% all trips

Existing peak hour trips p.a. (m) 30

Existing off-peak hour trips p.a. (m)

Elasticity of demand as $f$ (change in GC)

New peak hour trips p.a. (m)

New off-peak hour trips p.a. (m)

Total trips p.a. with free entry ( $\%$ increase)

\section{Cost data (a)}

Average fare (\$)

Licence fee per trip (\$)

Average cost (\$)

Value of wait time per taxi (\$/minute)

$A C=F-L F$

17.77

Normal wait time (minutes)

VWT

0.80

NWT

5.00

Excess wait time (minutes)

EWT

6.60

Equilibrium premium price (\$)

$\mathrm{X}$

5.50

Cost of normal wait time (\$ per taxi trip)

$\mathrm{NW}=\mathrm{NWT} \times \mathrm{VWT}$

4.00

Cost of excess wait time (\$ per taxi trip)

$\mathrm{EW}=\mathrm{EWT} \times \mathrm{VWT}$

5.28

GST (\$ per taxi trip)

Excise excluded

1.84

Externality cost (\$ per taxi trip)

Ecost

0.70

LRMSC

$A C+N W-G S T+E c o s t$

Fixed cost as \% of total cost

Variable costs as \% total cost 
Agenda, Volume 17, Number 2, 2010

Average generalised costs in peak hours

GC1

$\mathrm{AC}+\mathrm{NW}$

21.77

$\mathrm{GC} 2$

$\mathrm{AC}+\mathrm{NW}+\mathrm{LF}$

24.20

GC3

$A C+N W+L F+E W$

29.48

GC4

$\mathrm{GC} 3+\mathrm{X}$

34.98

GC5

LRMSC + NW

20.63

Average generalised costs in off-peak hours

GC1

$A C+N W$

21.77

GC2

$\mathrm{AC}+\mathrm{NW}+\mathrm{LF}$

24.20

GC6

$\mathrm{AC}-\mathrm{LF}+\mathrm{NW}$

19.34

GC7

$A C-L F+N W-G S T+E c o s t$

17.50 